\title{
A INFLUÊNCIA DA EDUCAÇÃO A DISTÂNCIA CORPORATIVA DO PORTAL CAPACIDADES NA PERSPECTIVA DO PARTICIPANTE
}

\author{
BRASÍLIA/DF MAIO/2018
}

\author{
Helen Miquelote - MCid - helen.miquelote@cidades.gov.br \\ Luana Landim Araújo - MCid - luana.araujo@cidades.gov.br \\ Ricardo de Sousa Carrijo Barbosa - MCid - ricardo.barbosa@cidades.gov.br
}

Tipo: Relato de Experiência Inovadora (EI)

Categoria: Pesquisa e Avaliação

Setor Educacional: EDUCAÇÃO CORPORATIVA

\begin{abstract}
RESUMO
Este artigo apresenta os resultados das avaliações de percepção dos participantes dos cursos a distância do Portal Capacidades, a fim de verificar a contribuição das atividades no desenvolvimento pessoal e atendimento das demandas no contexto profissional. Para isso foram selecionados cinco cursos da área de desenvolvimento urbano, utilizando questionário avaliativo constituído de uma escala gradativa de concordância. Os resultados apontaram para uma aprovação significativa da contribuição das atividades realizadas nos cursos a distância para o desenvolvimento pessoal e profissional.
\end{abstract}

Palavras-chave: Educação corporativa, Capacidades, desenvolvimento pessoal, desenvolvimento profissional, percepção. 


\section{INTRODUÇÃO}

O Programa Nacional de Capacitação das Cidades (PNCC) foi criado em 2007 com o intuito de agregar os diferentes programas e ações de capacitação promovidas pelo Ministério das Cidades. Diante dos desafios enfrentados para qualificação de agentes municipais e sociais no formato presencial, a capacitação a distância sobre os temas concernentes às políticas públicas urbanas se constituiu em uma das importantes estratégias para se mobilizar conhecimentos, metodologias e ferramentas gerenciais. Dessa forma, foi construído um ambiente virtual, capaz de congregar informações sobre os eventos, permitir a inscrição para as atividades, hospedar cursos a distância moderados e de autoinstrução, disponibilizar publicações e vídeos, a fim de viabilizar a maior interação do Ministério das Cidades com o público que busca se capacitar. Todas estas ferramentas e recursos foram incorporados ao Portal Capacidades (www.capacidades.gov.br).

Com isso, viabiliza aos técnicos e gestores em suas atividades de gerência, monitoramento, execução e avaliação de ações, programas e serviços demandados pela dinâmica urbana, a oportunidade de adquirir conhecimentos sobre diversos temas ligados ao planejamento e à gestão urbana. No âmbito do PNCC, foram capacitados mais de 235 mil técnicos municipais, agentes sociais e demais interessados que participaram de cursos, seminários, oficinas, teleconferências e palestras realizadas em todo o território nacional. O Portal Capacidades e o ambiente de Educação a Distância também atendem a comunidade acadêmica, com informações para o desenvolvimento de projetos e trabalhos vinculados aos programas e normativas governamentais na temática do desenvolvimento urbano.

\section{OBJETIVOS}

Apresenta-se neste artigo, a contribuição das atividades de educação a distância para o desenvolvimento dos agentes capacitados, para verificar se os conteúdos abordados nos cursos colaboraram com a aquisição de conhecimento e se a capacitação auxiliou nas demandas diárias dos participantes atreladas ao seu desenvolvimento pessoal em seu contexto profissional.

\section{REFERENCIAL TEÓRICO}

Os órgãos públicos federais possuem suas políticas de capacitação para técnicos e gestores municipais. Tradicionalmente, elas foram desenvolvidas com base em ações presenciais, por meio de seminários, reuniões, debates, oficinas, workshops, dentre 
outras. Entretanto, é fato que os orçamentos para estas ações ficam aquém do necessário para atender os 5.570 municípios existentes no Brasil (IBGE, 2018). A Educação a Distância $(\mathrm{EaD})$ é um meio eficiente e com custo efetivo para alcançar um número maior de pessoas em locais mais distantes. A EaD possui flexibilidade de horário, mais fluidez disciplinar e especialmente custos mais econômicos, principalmente quando comparados com as capacitações presenciais. Essa afirmação remete à possibilidade de oferecer aos técnicos e gestores municipais capacitações com variadas frentes de trabalho que agreguem valor à sua atuação como representante da administração pública de maneira mais eficiente.

Para Alexandrino (2016, p.237), "a ideia básica é que os controles a que está sujeita a administração pública, e os métodos de gestão que utiliza, acarretam morosidade, desperdícios, baixa produtividade (...)", indo contra a um dos princípios basilares da administração pública: o da Eficiência. Nesse sentido, observa-se que a Educação a Distância - como meio de capacitação dos técnicos e gestores municipais - vai ao encontro do princípio da Eficiência; pois visa, sobretudo, alcançar o maior número de técnicos e gestores municipais com o menor custo possível. O princípio da Eficiência foi inserido na Constituição Federal (CF) de 1988 pela Emenda Constitucional nํ19, de 04 de junho de 1988, por "consequência do modelo de administração pública conhecida como gerencial" (ALEXANDRINO, 2013, p. 237), que traduzia a desburocratização da administração pública.

Para Abrucio (1997, p.11), a administração pública gerencial está mais "direcionada à redução de custos e ao aumento da eficiência e produtividade da organização"; assim como para "o controle dos gastos públicos e a demanda pela melhor qualidade dos serviços públicos". É possível assim, ainda segundo Alexandrino (2013, p.237), vincular o princípio da Eficiência à economicidade prevista no artigo 70, caput, da CF, no que diz respeito à necessidade de uma atividade da administração pública mais simples, econômica e com ótimo aproveitamento no que concerne ao interesse público, pois "Eficiência tem como consectário a boa qualidade".

\section{METODOLOGIA}

O Programa Nacional de Capacitação das Cidades (PNCC), do Ministério das Cidades, capacita os agentes públicos e demais atores envolvidos na esfera do desenvolvimento urbano, principalmente, por meio da plataforma de educação a distância hospedada no Portal Capacidades. Com isso, é possível afirmar que "o PNCC se consolida com a ampliação de suas atividades, tendo em conta a criação da sua plataforma de educação a distância e dos aplicativos de grande alcance" (CUNHA, 2016. p.12). Dessa forma, é 
de fundamental importância conhecer a opinião dos participantes acerca das atividades disponibilizadas e, em especial, neste artigo, as questões relacionadas ao seu desenvolvimento pessoal e profissional.

Para este artigo, foram definidos cinco cursos relacionados à temática do desenvolvimento urbano. Os participantes responderam aos questionários avaliativos sobre os cursos, com a finalidade de verificar suas percepções acerca da contribuição dos conteúdos para o desenvolvimento dos seus conhecimentos e sua aplicação no contexto das atividades por eles realizadas, pois conforme afirma Richardson, apud Dalfovo (2008 p.8) "no planejamento deste tipo de estudo, o primeiro passo a ser dado é no sentido de identificar as variáveis específicas que possam ser importantes, para assim poder explicar as complexas características de um problema".

O questionário avaliativo consiste em seis perguntas com o objetivo de verificar se as atividades desenvolvidas no curso foram suficientes para a aprendizagem, bem como a assimilação dos conteúdos, por meio de uma escala gradativa de concordância. Outra variável investigada foi a relação entre as necessidades de aprendizagem e o assunto abordado nos cursos. A capacidade de ser um multiplicador do conhecimento adquirido foi um item destacado, além da reflexão crítica acerca da temática. Por fim, ressaltamos a utilização dos conhecimentos adquiridos na atividade profissional ou acadêmica.

Para análise dos dados, utilizou-se um método quantitativo, escolhido por ser "frequentemente aplicado nos estudos descritivos (aqueles que procuram descobrir e classificar a relação entre variáveis), os quais propõem investigar "o que é", ou seja, a descobrir as características de um fenômeno como tal" (RICHARDSON, 1989 apud DALFOVO, 2008,p.7). Os dados obtidos nas avaliações do Portal foram tabulados e os gráficos analisados.

\section{RESULTADOS E DISCUSSÃO}

Para verificar como os conteúdos auxiliam o público alvo em seu desenvolvimento pessoal e profissional, analisou-se cinco cursos na linha de Desenvolvimento Urbano, totalizando 1.807 participantes que responderam a avaliação. Segundo os resultados dos questionários avaliativos, os conteúdos apresentados nos cursos foram assimilados por $39 \%$ dos participantes que concordaram totalmente com a afirmativa. Para $58 \%$ dos participantes, a assimilação do conteúdo foi boa (Gráfico 1). Assim, verifica-se que houve assimilação do conteúdo por 1.763 participantes de um universo de 1.807. A aprendizagem significativa acontece quando o participante consegue agregar novos conhecimentos aos que ele já possui (COSTA, 2012). Assim, o elaborador de conteúdo 
deve ficar atento à linguagem e à forma de abordá-lo, visto que, por ser um curso a distância, o participante deverá ser capaz de compreender o assunto de forma autônoma e relacioná-lo com sua experiência inicial em seu ambiente de trabalho.

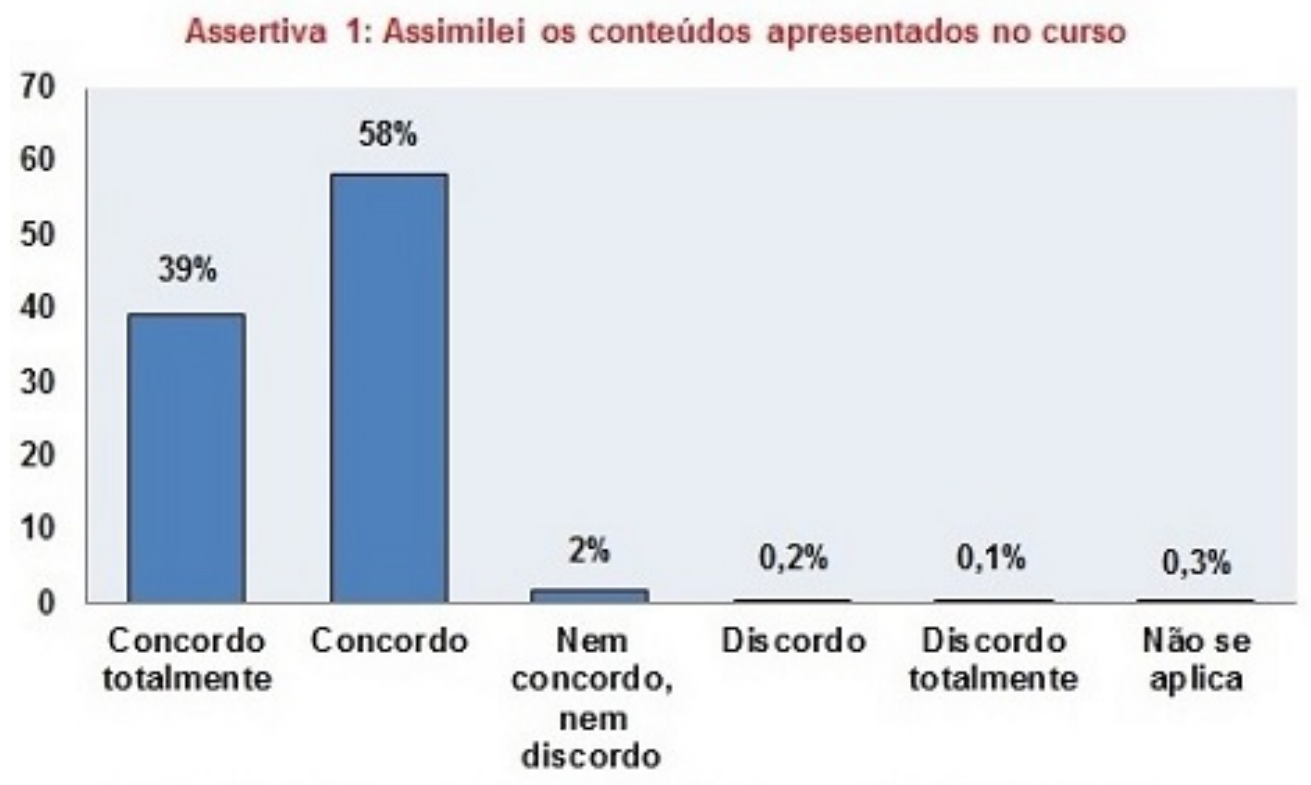

Gráfico 1: Nivel de concordância com relação a assimilação de conteúdo.

Acerca do desenvolvimento da capacidade de refletir criticamente sobre o conteúdo abordado, 33\% dos participantes afirmam serem totalmente capazes de realizar uma reflexão crítica. Ao responder o questionário avaliativo, $61 \%$ concordam sobre a capacidade de fazerem uma reflexão crítica sobre o assunto proposto no curso (Gráfico 2). O material disponível no Ambiente Virtual de Aprendizagem (AVA), assim como as atividades desenvolvidas para a formação do pensamento crítico-reflexivo contribuem para que o participante desenvolva maneiras mais colaborativas, responsáveis e éticas em seu ambiente de trabalho. Além disso, busca-se, por meio da capacitação, contribuir para que se tornem profissionais críticos e morais capazes de refletirem criticamente sobre as decisões que serão tomadas em seu ambiente de trabalho (CLOSS, 2010). 
Assertiva 2: Desenvolvi capacidade de refletir criticamente sobre o conteúdo abordado.

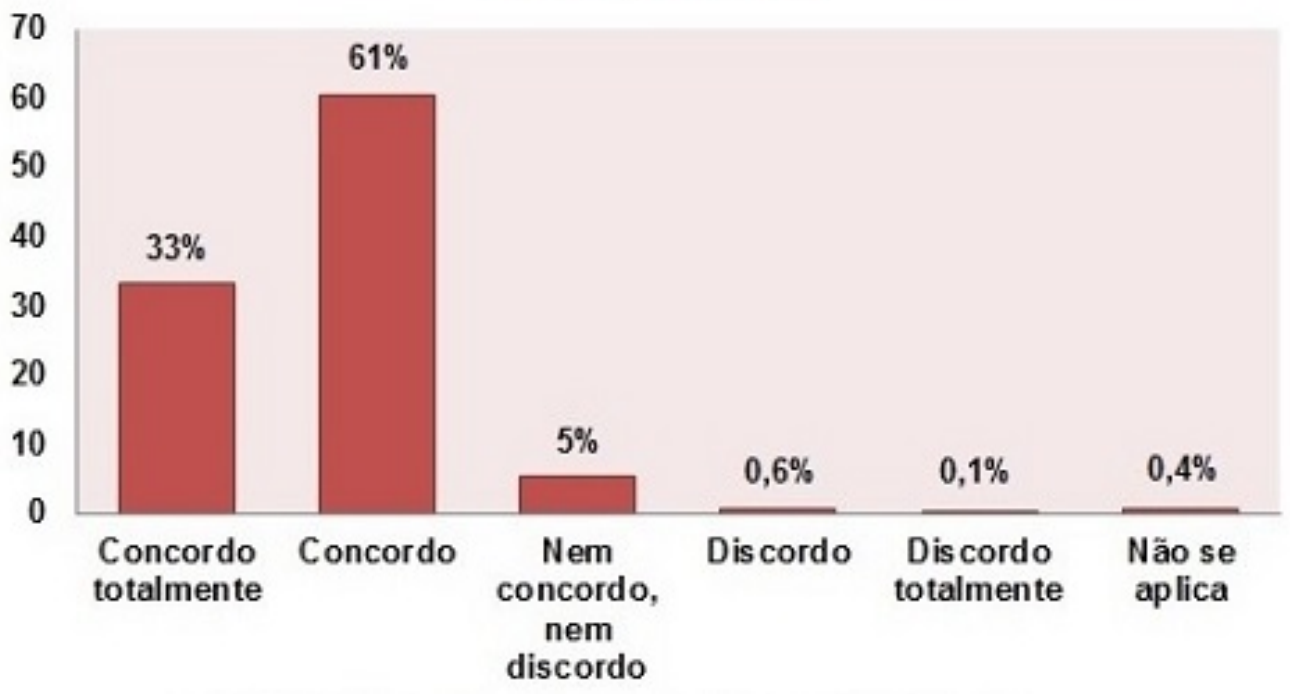

Gráfico 2: Nivel de capacidade de realizar reflexão crítica.

Os assuntos envolvendo o desenvolvimento urbano devem ser elaborados a fim de atender as demandas dos profissionais das áreas correlacionadas, proporcionando aos participantes dos cursos o atendimento de suas necessidades relacionadas aos temas específicos, como por exemplo, saneamento básico, estudo de impacto de vizinhança, dentre outros. Assim, para $60 \%$ dos participantes, essa necessidade de aprendizagem foi satisfatória e para 34\% foi totalmente satisfatória (Gráfico 3). Os cursos a distância disponíveis no Portal Capacidades visam auxiliar as necessidades de aprendizagem dos participantes. No entanto, a capacitação continuada se faz necessária e de fundamental importância, frente aos inúmeros desafios que a temática do desenvolvimento urbano apresenta aos envolvidos.

Assertiva 3: $O$ curso atendeu as minhas necessidades de aprendizagem sobre $o$ assunto abordado.

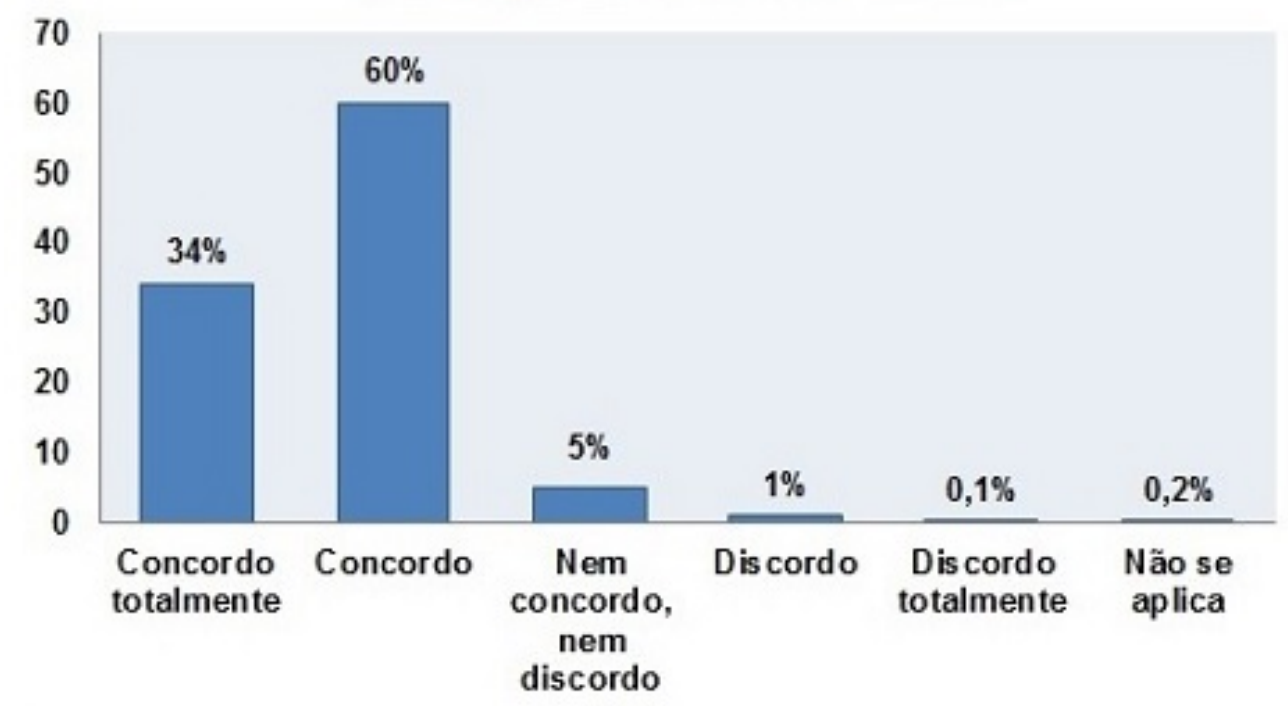

Gráfico 3: Nivel de concordância sobre 0 atendimento das necessidades de aprendizagem. 
Devido ao foco voltado para agentes públicos municipais, estaduais e federais, as atividades proporcionam aos participantes que os conhecimentos adquiridos sejam efetivamente aplicados na atividade profissional diária. Assim, 51\% dos participantes concordam que os conhecimentos adquiridos estão sendo utilizados diariamente em sua rotina de trabalho e $43 \%$ concordam totalmente com essa afirmação. (Gráfico 4).

Assertiva 4: Os conhecimentos adquiridos serão utilizados na minha atividade profissional (ou acadêmica)

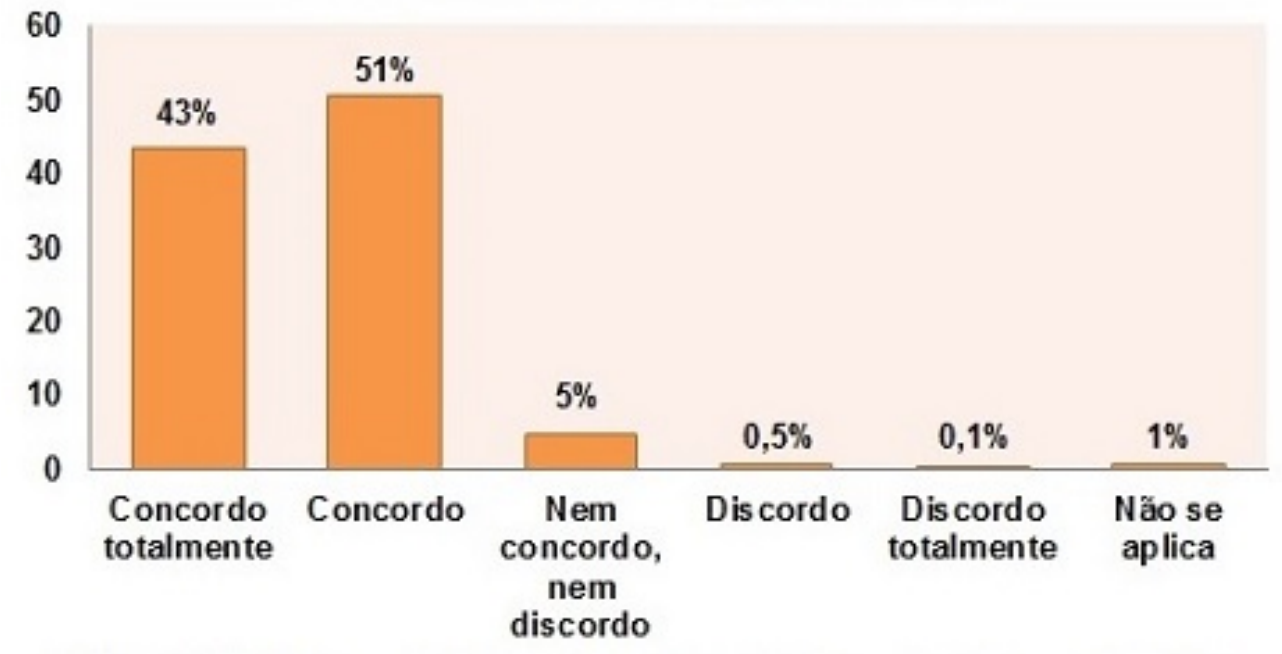

Gráfico 4: Nivel de concordância sobre a utilização dos conhecimentos na prática.

Além de utilizar os conhecimentos adquiridos no dia-a-dia, a aprendizagem é complementada com a capacidade de compartilhar o que aprendeu. Dentro dessa perspectiva, $89 \%$ dos participantes concordam que são capazes de compartilhar os conhecimentos adquiridos nos cursos do Portal Capacidades com outras pessoas. Frente a isso, os envolvidos no ambiente de trabalho ou na rotina acadêmica do participante também se beneficiam com o conteúdo aprendido e estudado (Gráfico 5). 
Assertiva 5: Sinto-me capaz de compartilhar os conhecimentos adquiridos com outras pessoas.

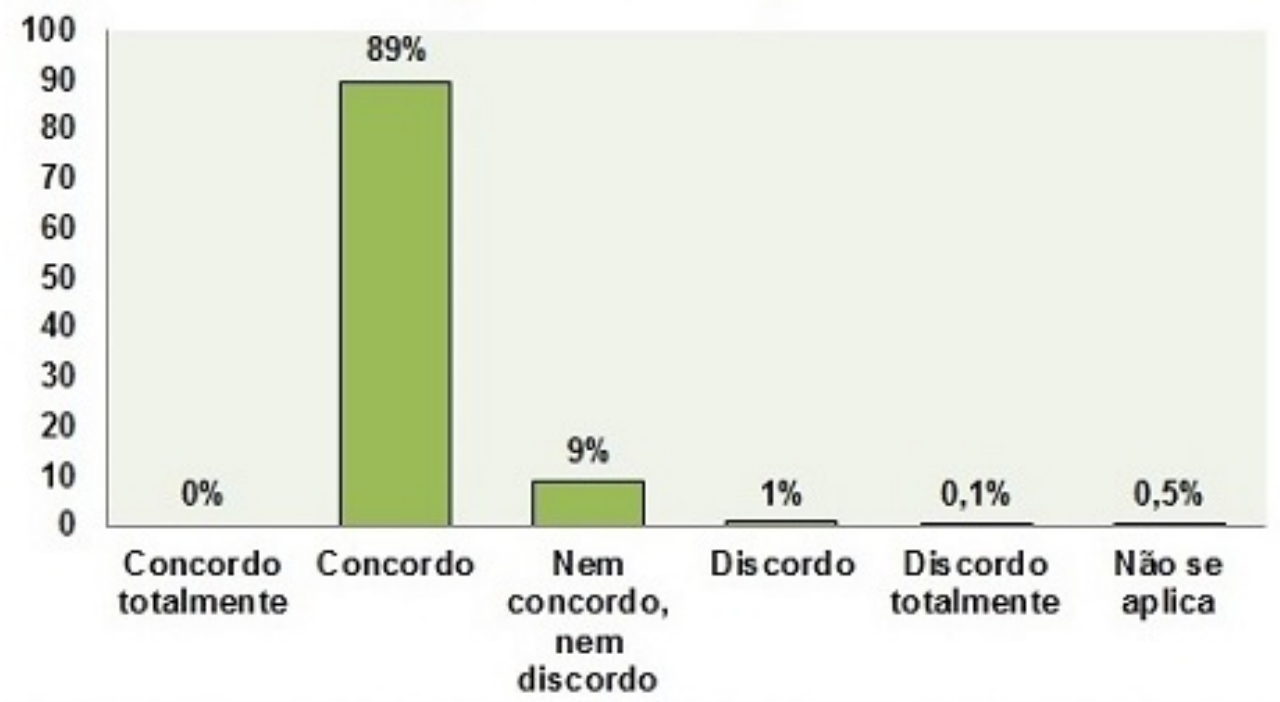

Gráfico 5: Nivel de concordância sobre a capacidade de compartilhar os conhecimentos.

Mensurar a aprendizagem não é tarefa fácil, devido ao seu caráter subjetivo. Realizar essa tarefa em educação a distância constitui um desafio. Assim, busca-se disponibilizar textos que contribuam para aquisição de conhecimento e reflexão, vídeos com explicações e exemplos de casos práticos, além de questionários avaliativos abordando o conteúdo disponibilizado. Todo o processo realizado pelo participante é importante para que chegue ao final do curso preparado para os desafios de sua rotina profissional. Verificou-se que as atividades propostas pelos cursos no AVA foram totalmente suficientes para $30 \%$ dos participantes e suficientes para $60 \%$ (Gráfico 6).

Assertiva 6: As atividades desenvolvidas no curso foram suficientes para minha aprendizagem.

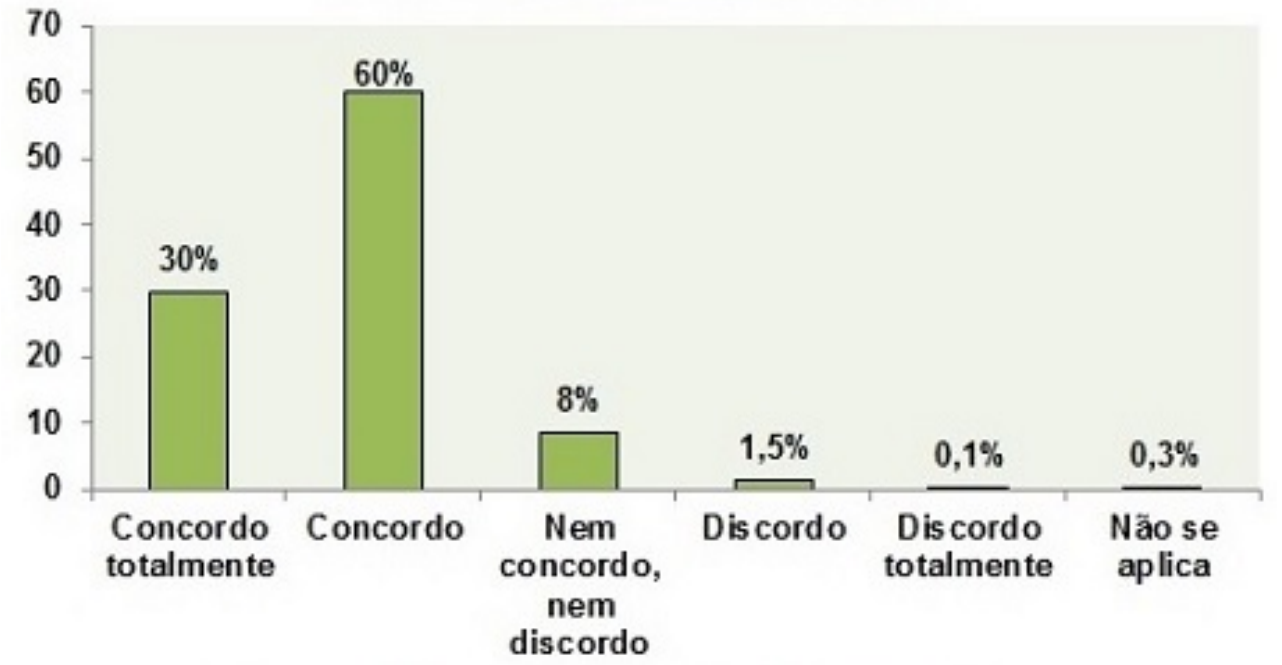

Gráfico 6: Nivel de concordância sobre a aprendizagem. 


\section{CONSIDERAÇÕES FINAIS}

Desde sua criação, em 2007, pelo Ministério das Cidades, o Programa Nacional de Capacitação das Cidades (PNCC) vem realizando esforços para capacitar agentes públicos e sociais em todas as esferas do Poder Público. Além disso, o Programa busca, por meio da ação de capacitação, implementar a Política Nacional de Desenvolvimento Urbano. O Programa alcançou até o presente momento mais de 205 mil inscritos nas atividades oferecidas pelo Portal Capacidades em todo o território nacional. Devido a extensão territorial do país, o Programa pretende continuar capacitando nas mais diversas áreas do desenvolvimento urbano. Para isso, há a necessidade de investimentos em melhorias estruturais e materiais, principalmente na tecnologia.

Há muito a ser feito, pois ainda não foram atingidos todos os municípios. Frequentemente, são realizadas ações de divulgação por meio de mala direta, notícias no Portal Capacidades e redes sociais, a fim de alcançar o maior número de pessoas e municípios, ampliando o alcance do Programa. Assim, há grandes desafios que podem ser enfrentados, pois ao reconhecer a importância do Programa e seu alcance, medidas de aperfeiçoamento e ampliação da estrutura poderão ser adotadas. Além disso, há a necessidade de investimento na capacitação dos servidores responsáveis por toda a estrutura do Portal Capacidades.

Ao verificar a importância de apoio e suporte ao participante, faz-se necessário ampliar a visão dos servidores que atuam nessa área, proporcionando condições para o desenvolvimento de uma consciência crítica e reflexiva para que eles possam enfrentar os desafios existentes também no seu local de trabalho. Verifica-se, com isso, a dimensão do Capacidades, pois atua tanto externa quanto internamente, envolvendo todos os atores a buscarem a eficiência e efetividade nos serviços prestados à sociedade o que corrobora a eficácia do Programa.

\section{REFERÊNCIAS BIBLIOGRÁFICAS}

ABRUCIO, F. L. O impacto do modelo gerencial na administração pública. Um breve estudo sobre a experiência internacional recente. Cadernos ENAP; n. 10. 52 p. Brasília, $1997 . \quad$ Disponível em: $<$ http://antigo.enap.gov.br/downloads/ec43ea4fAbrciocad\%2010.pdf >. Acesso em: 13 abr. 2018.

ALEXANDRINO, M.; PAULO, V. Direito administrativo descomplicado. 24 edição, revisada e atualizada. Rio de Janeiro: Forense. São Paulo: MÉTODO, 2016. 
BRASIL. Constituição Federal de 1988. Promulgada em 5 de outubro de 1988. Disponível em: $<$ http://www.planalto.gov.br/ccivil_03/constituicao/constituicaocompilado.htm $>$. Acesso em: 09 abr. 2018.

CLOSS, L.Q.; ANTONELLO, C. S. Aprendizagem transformadora: a reflexão crítica na formação gerencial. Cad. EBAPE. BR, Rio de Janeiro, v. 8, n. 1, p. 19-37, mar. 2010 .

Disponível

em:

$<$

http://www.scielo.br/scielo.php?script=sci_arttext\&pid=S1679-39512010000100003\&/ng= pt\&nrm=iso >. Acesso em: 11 abr. 2018.

COSTA, J. E. P. A. A teoria da Assimilação: construindo redes de saberes no contexto da educação digital. Dissertação de Mestrado. João Pessoa, 2012. Disponível em: <http://tede.biblioteca.ufpb.br/bitstream/tede/4750/1/arquivototal.pdf>. Acesso em: 11 abr. 2018.

CUNHA, E. P. Capacitação de agentes públicos para a implementação da nova política urbana: uma análise dos resultados alcançados. Trabalho de conclusão de curso. Escola Nacional de Administração Pública (ENAP). Brasília: jun. 2016. Disponível em:<http://repositorio.enap.gov.br/bitstream/1/2484/1/Egla\%C3\%ADsa.pdf>. Acessoem: 18 abr. 2018.

DALFOVO, M. S.; LANA, R. A.; SILVEIRA, A. Métodos quantitativos e qualitativos: um resgate teórico. Revista Interdisciplinar Científica Aplicada, Blumenau, v.2, n.4, p.01-13, Sem II. 2008 ISSN 1980-7031. Disponível em: $<$ http://rica.unibes.com.br/index.php/rica/article/view/243/234> . Acesso em: 17 abr. 2018.

IBGE, Instituto Brasileiro de Geografia e Estatística. Disponível em: $<$ https://www.ibge.gov.br/estatisticas-novoportal/por-cidade-estado-estatisticas.html $>$. Acesso em: 18 abr. 2018. 